\title{
FAHP in Multi-Criteria Inventory Classification for Storage Layout
}

\author{
Sirarat Nitkratoke ${ }^{1}$, Prasert Aengchuan ${ }^{2, *}$ \\ ${ }^{1}$ School of Mechanical and Process System Engineering, Institute of Engineering, Suranaree University of \\ Technology, Nakhon Ratchasima, Thailand \\ ${ }^{2}$ School of Manufacturing Engineering, Institute of Engineering, Suranaree University of Technology, Nakhon \\ Ratchasima, Thailand $*$ Corresponding author
}

\begin{abstract}
.
Purpose of this study is to propose the inventory layout after the inventory were classified when multi-criteria are considered. Fuzzy Analytic Hierarchy Process (FAHP) was applied to analyse the pairwise comparison of criteria weight. Trapezoidal fuzzy numbers were used to define the linguistic score, which is obtained opinion of experts in inventory control field. The considered criteria were eliminated from 8 to 4 for the weight of importance in multi-criteria $A B C$ inventory classification for classifying the Ultra High Temperature (UHT) milk inventory in a distribution center. The last process will be allocating the items into the multi-layer storage by using vertical class-based policy. The proposed model is illustrated by applying to 33 brands of UHT milk products from a distribution center in one of department stores in Thailand. The result of the FAHP method shows that 4 criteria such as ordering cost, selling volume, perishability and opportunity cost are the most criteria that the inventory manger in this company concern. For classification, total score for each brand after the normalization changed 27 brands' order. The changing order made 8 out of 33 brands moved to another class. After allocating the inventory, the layout has obviously changed on the $4^{\text {th }}$ to $6^{\text {th }}$ layer. The results of the proposed model show that FAHP for multi-criteria inventory classification can be applied to the $\mathrm{ABC}$ inventory classification method. According to the opinion of specialists, the proposed method can be deployed to improve efficiency of inventory control.
\end{abstract}

Keywords: ABC classification, FAHP, inventory layout, Multi-criteria decision making 


\section{Introduction}

Storage layout planning is one of the most important issues to the organization that work with inventory or have a huge warehouse. Assigning products to the right location enhances the product picking performance and save process time that can reduce cost. The organization has different policies for storage assignment depending on the suitable policy for their company.

The famous and simple inventory classification method that widely used is ABC classification. $\mathrm{ABC}$ method separates the inventory into 3 classes by considering on annual usage of each item. But in fact, each of the products has limitation or condition that makes it need more consideration than others. So, only criterion "Annual usage" could not be used for considering the whole warehouse. Many criteria such as lead time, unit cost, obsolescence, availability, limitation, substitutability, perishability, commonality, opportunity cost, ordering cost and selling volume were applied to the multi-criteria decision making to classify the items.

Several tools have been applied to develop multi-criteria decision making (MCDM) for the ABC inventory classification such as analytic hierarchy process (AHP) (Saaty, 1980), FAHP (Buckley, 1985), bi-criteria matrix (Flores et al., 1987), weighted linear optimization called RModel and Ng-Model (Ramanathan, 2006), (Ng, 2007), the developing of Ng-model by nonlinear model (Hadi-Vencheh, 2010).

\subsection{Class-based storage layout policy}

For make simple class-based storage layout, there are 2 geometry-shape models that simply to be used for storage layout which is vertical ABC class-based storage and horizontal class-based storage as shown in Fig. 1 (Chan et al., 2011). The vertical ABC class-based policy reduces the using of the ladder or forklift for picking up the products. This suitable for the warehouse that have multi-level rack. Horizontal class-based storage is different from the vertical class-based on the alignment of the product. This policy is good to be used in the small warehouse or with the single level warehouse.

Figure 1: Vertical class-based storage layout (A) and horizontal class-base storage layout (B).

(A)

\begin{tabular}{|l|}
\hline C \\
\hline B \\
\hline \\
A A \\
\hline
\end{tabular}

(B)

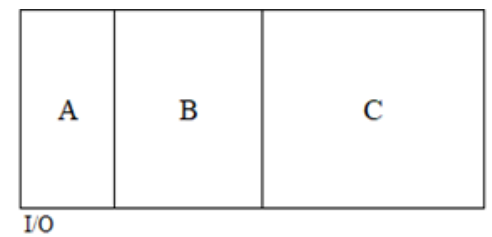

Source: Chan et al. 2011

\subsection{Fuzzy Analytic Hierarchy Process (FAHP)}

FAHP is a multi-criteria method analysis, which is based on the additive process to evaluate data. AHP is used for solving complex problems by decomposing it into sub-problem.

Although AHP is simple to use, it is hard to apply to the case of many decision alternatives. The uncertain preference from each decision maker affect to the AHP method which is a big gap of AHP implementation. The integrating of Fuzzy theory to AHP was proposed to solve this problem by using triangular fuzzy numbers to scoring pairwise questionnaire to calculate criteria's weight. The determining of the linguistic words to be fuzzy membership function. The triangular fuzzy number is the fuzzy set that used in the operation to calculate before using the AHP. To plus, minus, multiply and inverse triangular fuzzy will be as follows. These statements proposed by (Zadeh, 1965) and the operation of fuzzy set is shown in eq. 1-6. 
Let fuzzy set A: $\tilde{\mathrm{A}}=(\mathrm{a}, \mathrm{b}, \mathrm{c})$ and fuzzy set $\mathrm{B}: \tilde{\mathrm{B}}=(\mathrm{x}, \mathrm{y}, \mathrm{z})$

$$
\begin{gathered}
\tilde{A} \square \tilde{B}=[\mathrm{a}+\mathrm{x}, \mathrm{b}+\mathrm{y}, \mathrm{c}+\mathrm{z}] \\
\tilde{A} \square \tilde{B}=[\mathrm{a} \times \mathrm{x}, \mathrm{b} \times \mathrm{y}, \mathrm{c} \times \mathrm{z}] \\
\tilde{A} \square \tilde{B}=[a-x, b-y, c-z] \\
\tilde{A} \square \mathrm{r}=[\mathrm{a} \times \mathrm{r}, \mathrm{b} \times \mathrm{r}, \mathrm{c} \times \mathrm{r}] \\
d(\tilde{A}, \tilde{B})=\sqrt{\frac{1}{3}\left[(a-x)^{2}+(b-y)^{2}+(c-z)^{2}\right]} \\
\tilde{A}^{-1}=[\underline{1}, \underline{1}, \underline{1}] \\
c b a
\end{gathered}
$$

The operation of FAHP, firstly we start with making a pairwise comparison matrix of criteria for hierarchy process. Then, assign the linguistic score to compare each pair of criteria as $\tilde{A}$ in eq. 7 .

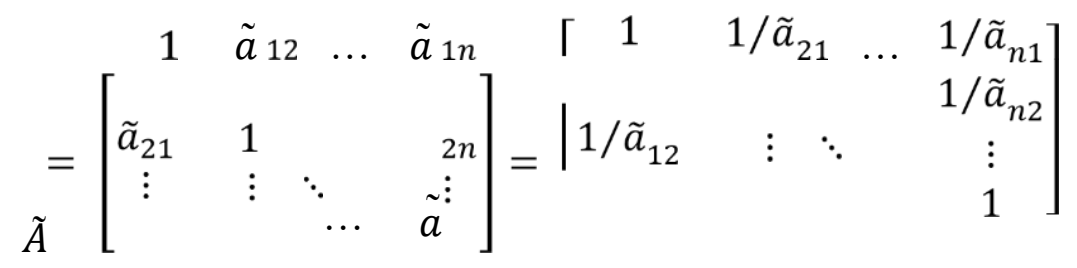

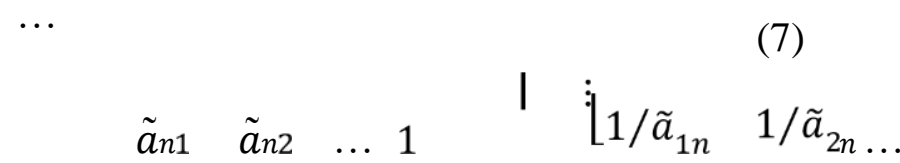

$$
\begin{aligned}
& \tilde{5}^{-1}, \tilde{4}^{-1}, \tilde{3}^{-1}, \tilde{2}^{-1}, \tilde{1}^{-1}, \tilde{1}, \widetilde{2}, \tilde{3}, \tilde{4}, \widetilde{5}, 1, \quad i \neq j \\
& \tilde{a}_{i j}=\{ \\
& 1 \quad i \quad=j
\end{aligned}
$$

Geometric mean technique was used to define fuzzy geometric mean and its weight of each was proposed by (Hsieh, 2004). The $\tilde{a}_{i j}$ is the fuzzy comparison value of criteria $i$ to criteria $j$ whereas $\tilde{r_{i}}$ is the geometric mean of fuzzy comparison for criterion $i$ and $\tilde{w}_{i}$ is fuzzy weight of each criterion $i$.

$$
\begin{array}{r}
1 \\
\tilde{r_{i}}=\left(\tilde{\mathrm{a}}_{\mathrm{i} 1} \square \ldots \square \tilde{\mathrm{a}}_{\mathrm{ij}} \square \ldots \square \tilde{\mathrm{a}_{\mathrm{in}}}\right)^{-} \\
\tilde{w_{i}}=\tilde{r_{i}} \square\left[\tilde{r_{1}} \square \ldots \square \tilde{r_{i}} \square \ldots \square \tilde{r_{n}}\right]^{-1}
\end{array}
$$

In this research, we applied the FAHP technique for multi-criteria decision making to determine the weight of considered criteria for classifying the 33 brands of UHT milk products into 3 groups by the ABC classification method. The data were collected by 4 invited experts. After that the weight of criteria is used for classifying the UHT milk brands by the method called normalizing to aggregate the overall scores for each brand. Then all products will be allocated by using the vertical class-based storage layout policy. 


\section{Method}

The proposed model was applied to classifying and allocating the UHT milk inventory in a distribution center. 274 items are grouped to be 33 brands to avoid the complicated of control and purchasing. The required storage space for each brand is shown in the column 2 of Tab.2.

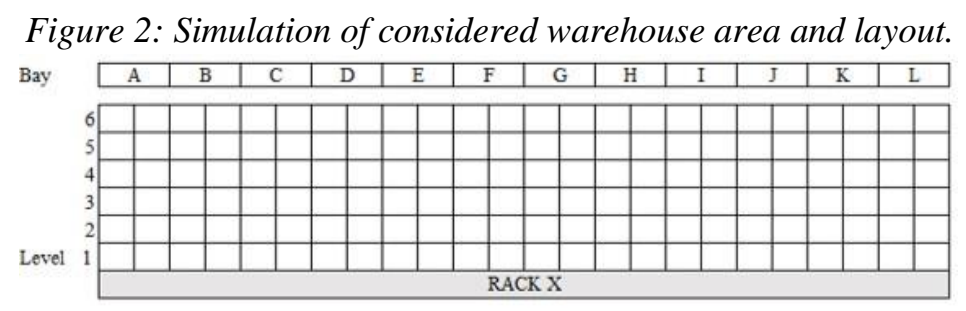

In the warehouse 2 racks of the first zone are the area to be considered. Each rack has 12 bays with 6 levels, include with the floor. Each bay can contain 2 pallets of product. It means 288 pallets can be stored in those racks. In Fig. 2 shows the depot address. The dimension of each bay is $2.5 \mathrm{~m}$. width $1.2 \mathrm{~m}$. depth and $1.0 \mathrm{~m}$. height. The company's picking policy for the $1^{\text {st }}$ and $2^{\text {nd }}$ floor is manual picking and for the $3^{\text {rd }}$ to $6^{\text {th }}$ floor the forklift is used for taking the pallets down for manual picking up then put back the pallets.

Three experts were invited for the evaluation of this study. All of them are working in the inventory control field and two of them are in charge with the inventory in the case study warehouse. Firstly, they have requested to eliminate 8 criteria; annual usage, lead time, limitation of product, opportunity cost due to lack of product, perishability, commonality, ordering cost, selling volume into 4 criteria they are concerned for their inventory control. To figure out the criteria weight, they have asked to scoring the fuzzy pairwise comparison matrix of 4 criteria. Then the triangular fuzzy numbers were used to define the linguistic scores as shown in Tab.1 and the fuzzy decision was solved by eq. 7 and 8 .

Table 1: Membership function of comparison score

\begin{tabular}{|c|c|c|}
\hline Fuzzy number & Linguistic word & Membership Function \\
\hline$\tilde{1}$ & Equally important & $(1,1,1)$ \\
\hline$\tilde{2}$ & Weakly important & $(1,2,3)$ \\
\hline$\tilde{3}$ & More important & $(2,3,4)$ \\
\hline$\tilde{4}$ & Strongly important & $(3,4,5)$ \\
\hline$\tilde{5}$ & Absolutely important & $(4,5,6)$ \\
\hline
\end{tabular}

For another part a staff who is in charge with UHT milk inventory is the person to grading each brand of UHT milk for classification by the criteria they selected as the important criteria. UHT milk brands have graded under each criterion by the 5-grade scale as in eq. 9 .

$$
\begin{aligned}
G_{\mathrm{ij}} & =\{\text { Very High; High; Medium; Low; Very Low }\} \\
& =\{5,4,3,2,1\},(\mathrm{i}=1,2,3, \ldots, \mathrm{N}),(\mathrm{j}=1,2,3,4)
\end{aligned}
$$

Following the policy for the higher level of rack require more wasting time and labor for picking. So, the important product should be put in the lower rack as much as it can. The vertical class-based storage is suitable for the layout planning. Authors make illustrations in Rectangleshape. 


\section{Results and Discussion}

\subsection{Criteria weight}

For the first task, the 4 criteria that all experts were eliminated due to they have mostly concerned for their product are perishability, ordering cost, selling volume, and opportunity cost due to lack of product. After using the FAHP fuzzified the criteria's weights were shown in Fig.4. Ordering cost is the most criterion that they are concerning about for UHT milk inventory with the weight 0.389 or $38.9 \%$, selling volume, opportunity cost and perishability contained the weight $0.27,0.213$ and 0.128 respectively.

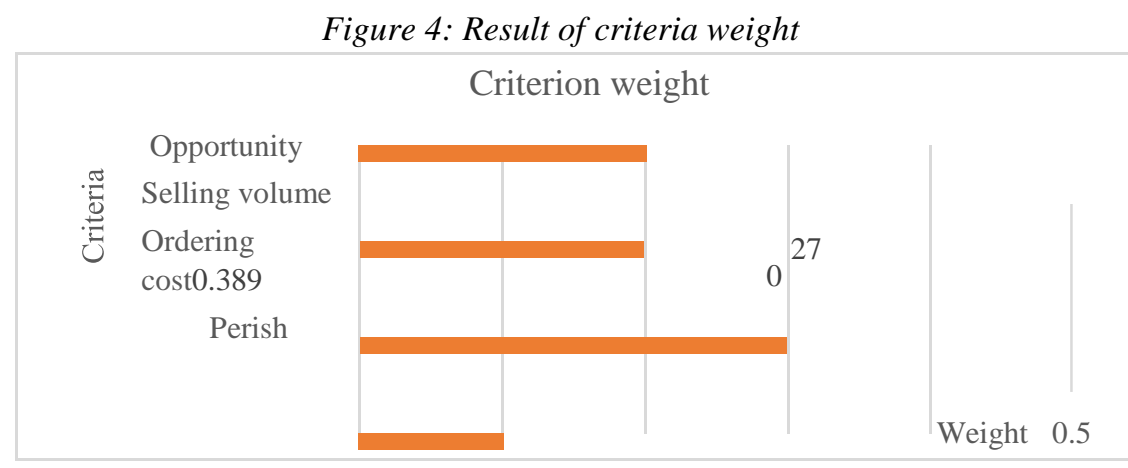

\subsection{The classification}

By considering 4 criteria and its weight from the first results, each brand was scored under 4 important criteria as shown in Tab. 2. After the normalization method was applied, the total score for items are shown in the $3^{\text {rd }}$ column of the table. The result of the re-classification for each brand is shown in the last column. The traditional ABC (TABC) method comparison with the proposed model represented that 8 out of 33 brands are re-classified, 1 from class $\mathrm{A}$ are moved to B-class. 1 brand from class B are moved to A. 3 from B-class regrouped to $\mathrm{C}$ and 3 of C-class are moved up to B-class.

For TABC the number of brands is orderly represented from 1 to 33 by the most usage to the least. In the proposed model, after integrated all criteria to be total score the new ranking as showed in the $5^{\text {th }}$ column of Tab. 2 has obliviously changed. Only 5 out of 33 brands stay in the same with TABC rank.

Table2: Result of classification table

\begin{tabular}{|c|c|c|c|c|c|}
\hline \multirow{2}{*}{$\begin{array}{c}\text { Brand } \\
\text { No. }\end{array}$} & $\begin{array}{c}\text { Spaces } \\
\text { required } \\
\text { (units) }\end{array}$ & $\begin{array}{c}\text { Total } \\
\text { scores }\end{array}$ & $\begin{array}{c}\text { TABC } \\
\text { class }\end{array}$ & \multicolumn{2}{|c|}{$\begin{array}{c}\text { Proposed } \\
\text { model }\end{array}$} \\
\cline { 4 - 6 } & & & & Rank & class \\
\hline 1 & 34 & 0.903 & $\mathrm{~A}$ & 1 & $\mathrm{~A}$ \\
\hline
\end{tabular}

\begin{tabular}{|c|c|c|c|c|c|}
\hline \multirow{2}{*}{$\begin{array}{c}\text { Brand } \\
\text { No. }\end{array}$} & $\begin{array}{c}\text { Spaces } \\
\text { required } \\
\text { (units) }\end{array}$ & $\begin{array}{c}\text { Total } \\
\text { scores }\end{array}$ & $\begin{array}{c}\text { TABC } \\
\text { class }\end{array}$ & \multicolumn{2}{|c|}{$\begin{array}{c}\text { Proposed } \\
\text { model }\end{array}$} \\
\cline { 4 - 6 } & & & & Rank & class \\
\hline 18 & 3 & 0.466 & $\mathrm{C}$ & 15 & $\mathrm{~B}$ \\
\hline
\end{tabular}




\begin{tabular}{|c|c|c|c|c|c|}
\hline 2 & 32 & 0.811 & $\mathrm{~A}$ & 2 & $\mathrm{~A}$ \\
\hline 3 & 28 & 0.776 & $\mathrm{~A}$ & 3 & $\mathrm{~A}$ \\
\hline 4 & 27 & 0.772 & $\mathrm{~A}$ & 4 & $\mathrm{~A}$ \\
\hline 5 & 20 & 0.703 & $\mathrm{~A}$ & 7 & $\mathrm{~B}$ \\
\hline 6 & 15 & 0.581 & $\mathrm{~B}$ & 11 & $\mathrm{~B}$ \\
\hline 7 & 13 & 0.729 & $\mathrm{~B}$ & 5 & $\mathrm{~A}$ \\
\hline 8 & 6 & 0.555 & $\mathrm{~B}$ & 13 & $\mathrm{~B}$ \\
\hline 9 & 3 & 0.539 & $\mathrm{~B}$ & 14 & $\mathrm{~B}$ \\
\hline 10 & 3 & 0.588 & $\mathrm{~B}$ & 10 & $\mathrm{~B}$ \\
\hline 11 & 10 & 0.631 & $\mathrm{~B}$ & 8 & $\mathrm{~B}$ \\
\hline 12 & 6 & 0.719 & $\mathrm{~B}$ & 6 & $\mathrm{~B}$ \\
\hline 13 & 4 & 0.564 & $\mathrm{~B}$ & 12 & $\mathrm{~B}$ \\
\hline 14 & 2 & 0.381 & $\mathrm{~B}$ & 20 & $\mathrm{C}$ \\
\hline 15 & 7 & 0.629 & $\mathrm{~B}$ & 9 & $\mathrm{~B}$ \\
\hline 16 & 5 & 0.441 & $\mathrm{~B}$ & 18 & $\mathrm{C}$ \\
\hline 17 & 4 & 0.414 & $\mathrm{~B}$ & 19 & $\mathrm{C}$ \\
\hline
\end{tabular}

\begin{tabular}{|l|l|l|l|l|l|}
\hline 19 & 2 & 0.449 & $\mathrm{C}$ & 16 & $\mathrm{~B}$ \\
\hline 20 & 2 & 0.449 & $\mathrm{C}$ & 17 & $\mathrm{~B}$ \\
\hline 21 & 2 & 0.345 & $\mathrm{C}$ & 29 & $\mathrm{C}$ \\
\hline 22 & 2 & 0.372 & $\mathrm{C}$ & 24 & $\mathrm{C}$ \\
\hline 23 & 2 & 0.329 & $\mathrm{C}$ & 30 & $\mathrm{C}$ \\
\hline 24 & 2 & 0.380 & $\mathrm{C}$ & 21 & $\mathrm{C}$ \\
\hline 25 & 1 & 0.355 & $\mathrm{C}$ & 25 & $\mathrm{C}$ \\
\hline 26 & 1 & $0 . .380$ & $\mathrm{C}$ & 22 & $\mathrm{C}$ \\
\hline 27 & 1 & 0.380 & $\mathrm{C}$ & 23 & $\mathrm{C}$ \\
\hline 28 & 1 & 0.329 & $\mathrm{C}$ & 31 & $\mathrm{C}$ \\
\hline 29 & 1 & 0.355 & $\mathrm{C}$ & 26 & $\mathrm{C}$ \\
\hline 30 & 1 & 0.251 & $\mathrm{C}$ & 33 & $\mathrm{C}$ \\
\hline 31 & 1 & 0.277 & $\mathrm{C}$ & 32 & $\mathrm{C}$ \\
\hline 32 & 1 & 0.355 & $\mathrm{C}$ & 27 & $\mathrm{C}$ \\
\hline 33 & 1 & 0.355 & $\mathrm{C}$ & 28 & $\mathrm{C}$ \\
\hline
\end{tabular}

\subsection{Inventory layout}

By using Vertical ABC class-based layout to allocate the UHT milk inventory. 5 brands of Aclass need more than $50 \%$ of the storage area because of high selling volume. It makes the first 3 level of the storage shelves are spared for A-class only. For B class products could be stored in the $4^{\text {th }}$ and $5^{\text {th }}$ level of the rack. For C-class products could be stored at the highest level of the rack. The storage layout of the proposed model is shown in Fig.5 (A).

Figure 5: Storage layout of ABC-classification (A), The storage layout of proposed model (B).

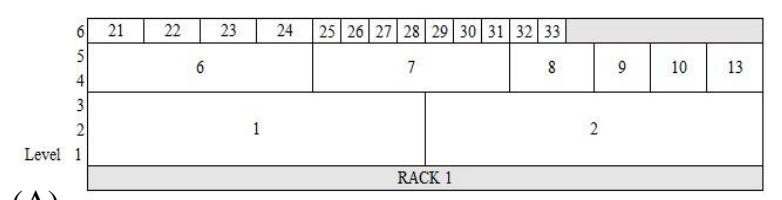

(A)

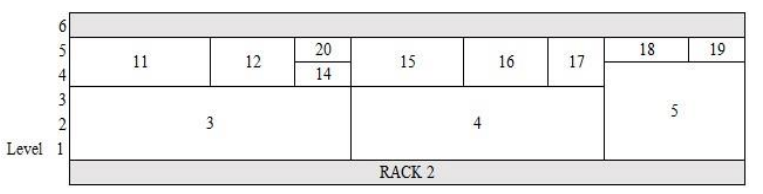

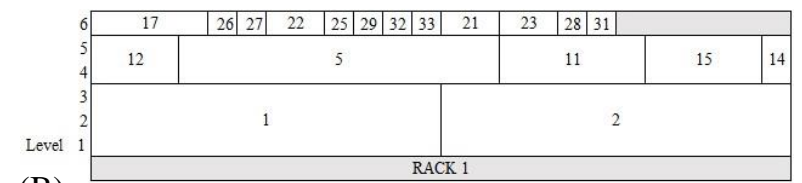

(B)

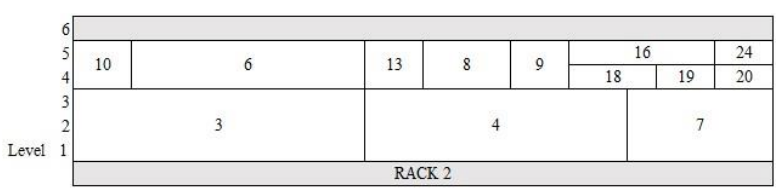

For Traditional classification showed that there are some products in brand number 5 stored in the $4^{\text {th }}$ level of rack because the storage in first 3 levels are not enough for A-class. Comparing the $4^{\text {th }}$ to $6^{\text {th }}$ level all of products are replaced because of the ranking are changed in $\mathrm{B}$ and $\mathrm{C}$ class. The storage layout of ABC-classification is shown in Fig.5(B).

\section{Conclusion}

FAHP technique can be applied to the ABC inventory classification method to determine the weight of criteria when the discussion has more than two criteria that need to be considered. By solving the model, criteria have got their own weight to use for the classification. The result of the ABC classification of the total score of the proposed method concludes that the FAHP 
ABC classification method can be deployed for the inventory classification with multi criteria to classify the inventory and to increase the efficiency of the inventory by obtaining manager or expert opinion. On the other hands, the results of the proposed model should study more on efficiency and effects of FAHP for multi-criteria to $\mathrm{ABC}$ classification. For further work, the efficiency of the model could be studied by comparing with the Traditional ABC classification.

\section{Acknowledgment}

This research was supported by Suranaree University of Technology. We would like to thank you for all the supported data and advices from the experts of a case study company.

\section{References}

[1] Saaty, T. L. (1980). The Analytic hierarchy process, McGraw-Hill, New York.

[2] Buckley, J. J. (1985). Fuzzy hierarchical analysis, Fuzzy Sets and Systems, vol.17(3), pp. 233-247.

[3] Flores, B. E. and Whybark, D. C. (1987). Implementing multiple criteria ABC analysis, Journal of Operations Management, vol.7(1), pp. 79-85.

[4] Ramanathan, R. (2006). ABC inventory classification with multiple-criteria using weighted linear optimization, Computers \& Operations Research, vol.33, pp.695-700. 
[5] Ng, W.L. (2007). A simple classifier for multiple criteria ABC analysis, European Journal of Operational Research, vol.177(1), pp. 344-353.

[6] Hadi-Vencheh, A. (2010). An improvement to multiple criteria ABC inventory classification, European Journal of Operational Research, vol.201(3), pp. 962-965.

[7] Chan, F.T.S., and Chan, H. K. (2011). Improving the productivity of order picking of a manual-pick and multi-level rack distribution warehouse through the implementation of class-based storage, Expert Systems with Applications, vol.38(3), pp. 2686-2700.

[8] Zadeh, L. A. (1965). Fuzzy sets, Information and control, vol.8(3), pp. 338-353.

[9] Hsieh, T. Y., Lu, S. T. and Tzeng, G. H. (2004). Fuzzy MCDM approach for planning and design tenders selection in public office buildings, International journal of project management, vol.22(7), pp. 573-584. 